\title{
On Notes for Authors
}

This editorial announces a number of important changes to the Notes for Authors:

\section{Scope of Powder Diffraction}

The scope of Powder Diffraction has been expended from "publishes articles, both experimental and theoretical, on the use of powder diffraction techniques for the characterization of crystalline materials" to "publishes articles, both experimental and theoretical, on the use of X-ray and related techniques for the characterization of materials.' Articles on the applications of X-ray, electron, neutron and other ionizing radiations for diffraction, fluorescence, reflectivity and scattering analyses of crystalline and non-crystalline materials are welcome. The expanded scope covers the many fields of materials analysis and makes Powder Diffraction a genuine international journal for materials characterization.

\section{Submission of Manuscripts}

We now have a "new Editor", Professor Deane K. Smith, appointed to deal with review and reprint articles. Those of you who are interested in the preparation of a review article or with suggestions for pre-1950 articles worthy for reprinting should contact Professor Smith directly.

Manuscripts on new diffraction data from all geographical regions should be submitted directly to the Editor for New Diffraction Data, Professor William E. Mayo (Rutgers University, Ceramics Department, Piscataway, NJ 088550909, USA). Direct submission to Professor Mayo speeds up the consideration of your manuscript for publication.

Another item to report here is that Professor Brian $\mathrm{H}$. O'Connor has agreed to serve as our new Editor for Southeast Asia (formally he was Editor for Australia and New Zealand). Authors in Southeast Asia, Australia and New Zealand are encouraged to submit their manuscripts directly to Professor O'Connor. Using the editor closest geographi- cally assists both the author and editor by simplifying the correspondence.

\section{Reviewing of Submissions}

To speed up the editing process and reduce the publishing time, the deadline for returning a revised manuscript by the corresponding author to the editor is reduced to three months. Manuscripts resubmitted after which time will be considered withdrawn. The editor will communicate with the corresponding author before taking action.

Another major modification to the editing procedures is that the Editor-in-Chief (EiC), not the individual editors, makes the final decision to formally accept a manuscript. This measure is essential for legal and quality assurance reasons. The sequence of events for the acceptance of a manuscript is as follows:

(1) Once the individual editor has received the author's final version which is acceptable in his opinion, he advises the corresponding author that the manuscript has been sent to the EiC with a recommendation that it be published.

(2) The EiC then formally advises the author that the paper has been accepted, assuming the $\mathrm{EiC}$ agrees to endorse the recommendation of the individual editor. Presumably, this will happen in most cases.

(3) Should the EiC require revisions or even fail to accept the paper, he would then communicate directly with the corresponding author and advise the individual editor of this status of the manuscript.

Detailed Notes for Authors are listed in this June 1999 issue. These notes are intended to help authors prepare their manuscripts in a form suitable for publication in Powder Diffraction.
Ting C. Huang Editor-in-Chief 